\title{
FALLAS DE MERCADO Y REGULACIÓN ECONÓMICA: ¿LA REGULACIÓN EJERCIDA POR EL GOBIERNO PERMITE LOGRAR UN MEJOR FUNCIONAMIENTO DE LOS MERCADOS?
}

\author{
MARKET FAILURE AND ECONOMIC REGULATION: DOES THE GOVERNMENT REGU- \\ LATION ALLOWS EXERCISED TO ACHIEVE A BETTER MARKET \\ PERFORMANCE?
}

\author{
Vladimir Rodríguez CAIRo* \\ Docente Asociado de la Facultad de Ciencias Contables \\ Universidad Nacional Mayor de San Marcos-UNMSM / Lima-Perú
}

[Recepción: Mayo de 2013/ Conformidad: Junio de 2013]

\begin{abstract}
RESUMEN
La regulación económica es una restricción legal que se impone a los agentes que participan en un mercado (como por ejemplo, el mercado de bienes y servicios o el mercado de capitales). Sin embargo, un aspecto relevante es que la regulación solo queda justificada ante la presencia de fallas de mercado que surgen por la presencia de externalidades, existencia de bienes públicos, falla de la competencia, asimetrías de la información y mercados incompletos.

Por otro lado, cada vez existe un mayor consenso en que los mercados y las empresas privadas constituyen la clave del éxito de una economía, y que el Estado desempeña un rol importante como complemento del mercado. No obstante, el accionar de los gobiernos de turno continúa siendo un motivo de controversias dentro de la pugna ideológica en el mundo.

En tal sentido, a continuación el presente artículo, analiza los antecedentes, el fundamentalismo de mercado, las fallas de mercado y regulación económica, el papel económico del Estado, y finalmente, el equilibrio entre Estado y mercado.
\end{abstract}

Palabras claves: fallas de mercado, regulación, económica, gobierno, funcionamiento de mercados

\begin{abstract}
The economic regulation has legal restrictions that impose to the agents that were involved in the market (like for example, the market of goods and services or the capital markets). However, there is an aspect relevant in the regulation we need to justify the present of the market failures that appear from the presents of the externalities, existence of public assets, failing competition, asymmetries and incomplete markets information.

That is way, there is mayor consent in the market and the private companies cooperated to the accomplishment of economy. That way the government makes a very important role in the market. However the government keeps doing a controversy subject in ideological conflict of world.

That why this article examines the background and fundamentalism, the failure the adjustment of the economy on the market, also the balance between market and government has a big role in the economy.
\end{abstract}

Keywords: market failures, regulation, economic, government, market operation

\footnotetext{
* Doctor en Derecho y Ciencia Política, UNMSM. Magíster en Economía, UNMSM. Director del Centro de Extensión Universitaria y Proyección Social (CEUPS). UNMSM.
} 


\section{ANTECEDENTES}

Tal como se aprecia en el diagrama siguiente, en los años treinta se da una pugna ideológica entre Keynes y Hayek.

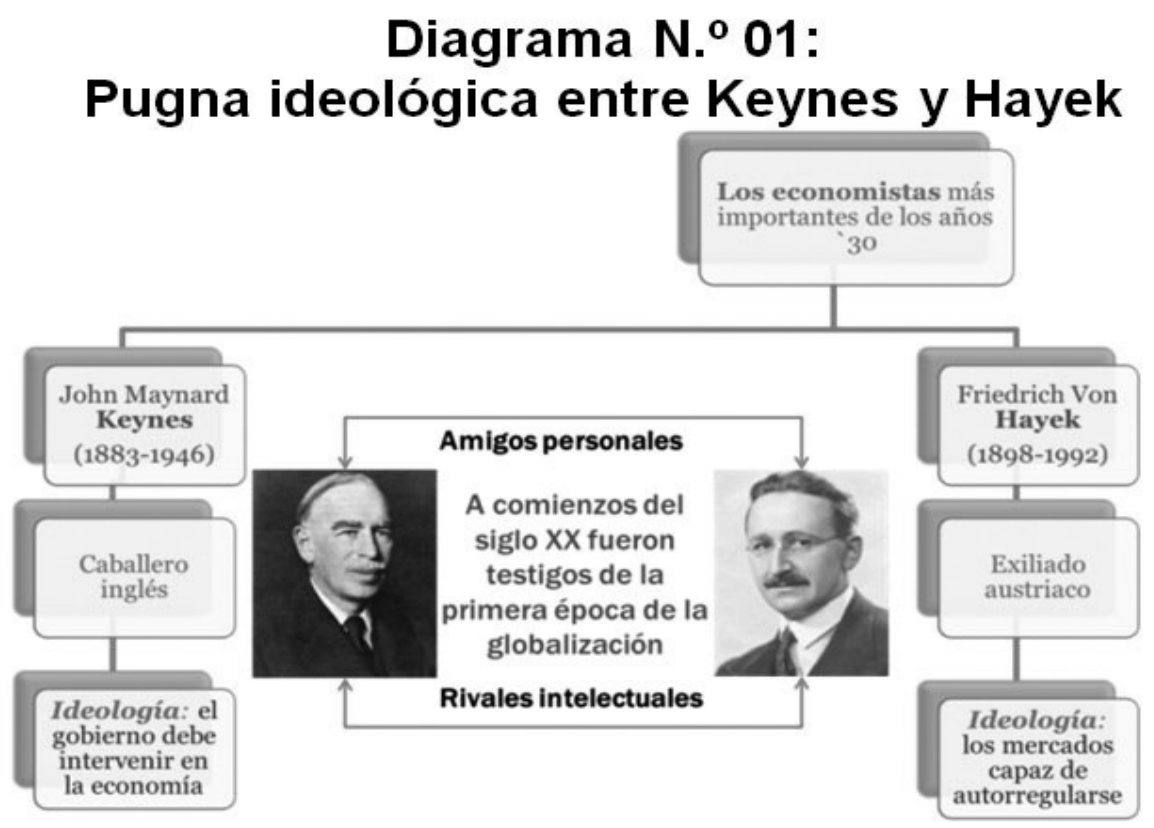

En general, el gran debate en la era de la Depresión $^{1}$ se produjo entre los conservadores fiscales, que querían contener el déficit, y los keynesianos que pensaban que el gobierno debía incurrir en déficits para estimular la economía (Stiglitz 2010: 94). La propiedad privada del capital y la libre empresa $y$, por otra, el control estatal de los medios de producción, constituyeron los principios opuestos que iban a guiar la política y la economía internacionales en el siglo XX, plasmadas en la guerra fría ${ }^{2}$.

Posteriormente, a finales de los ochenta e inicio de los noventa, el contexto mundial estuvo marcado por la caída del Muro de Berlín (1989) y la Desintegración de la URSS (1991), consecuentemente el fin de la guerra fría, ya que antes de estos hechos se presentó en el mundo una situación de disputa internacional creada entre las dos mayores superpotencias del mundo (EE.UU - URSS) por la hegemonía del mundo, donde los otros países debían ceder a uno de los polos de influencia. Un aspecto esencial de la ex Unión Soviética y el bloque del Este es que en los noventa se encontraban en transición a un sistema de mercado, es decir, en una transformación del rol del Estado en estas economías.

Por el contrario, hoy en día existe un mayor consenso en que los mercados y las empresas privadas constituyen la clave del éxito de una economía, mientras que el Estado desempeña un rol importante para lograr el mejor funcionamiento de los mercados. Sin embargo, similar a los años treinta, el accionar de los gobiernos de turno continúa siendo un motivo de controversias dentro de la pugna ideológica en el mundo.

\section{FUNDAMENTALISMO DE MERCADO}

En la actualidad, debido al avance de la informática y las telecomunicaciones, se concibe al mercado como el mecanismo (por ejemplo electrónico) a través del cual, compradores y vendedores, expresan su voluntad y se ponen de acuerdo en el precio y cantidad de un producto.

1 Los años de la depresión estimularon grandemente la acumulación y el uso sistemático de estadísticas como parte central de las políticas económicas.

2 La Guerra Fría es el estado de conflicto o desconfianza, próximo a operaciones de guerra abierta que se dio entre EE.UU. y la ex Unión Soviética después de la Segunda Guerra Mundial.

100/ QVIPURAMAYOC | Vol. 21(39) 2013 
Joseph Stiglitz ${ }^{3}$ (2008; 275-6) afirma que las ideas de fundamentalismo de mercado se reflejaban en la estrategia básica para el desarrollo (y para la gestión de las crisis y la transición del comunismo al mercado) defendida a principios de los ochenta por el FMI ${ }^{4}$, el Banco Mundial y el Tesoro de los Estados Unidos, una estrategia que muchos bautizaron como "neoliberalismo" o, debido a que sus principales defensores se encontraban todos en Washington, "El consenso de Washington". Ello implicaba la minimización de la función del gobierno, mediante la privatización de empresas de propiedad estatal y eliminar las normas del gobierno y las intervenciones en la economía.

Con la caída de los regímenes socialistas a fines de los 80 y principios de los 90, revivieron las viejas ideas del liberalismo; resurgió la idea de que un despliegue (de ideas) de fuerzas individuales, sin el freno del Estado, conducirá al bienestar colectivo o bien común.

Adicionalmente, Stiglitz (2010; 47) formula una crítica fuerte contra el FMI, afirmando que puede que el FMI cree en el fundamentalismo de mercado (que los mercados son eficientes, que se corri-

\section{Diagrama N. ${ }^{\circ} 02$ : Fundamentalismo de mercado vs. Ayuda del gobierno}

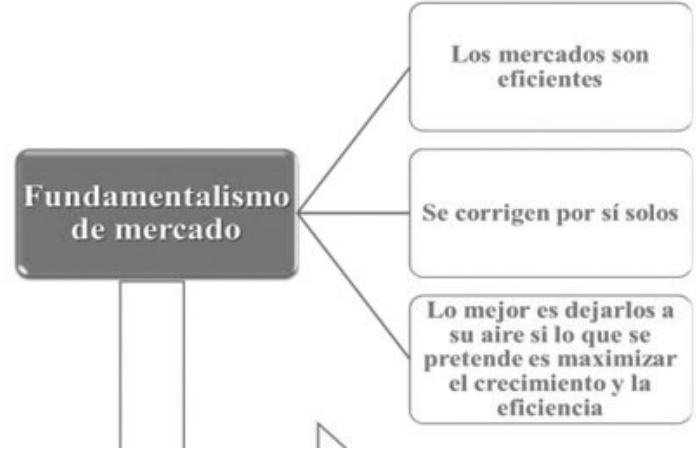

gen por sí solos, y que por consiguiente lo mejor es dejarlos a su aire si lo que se pretende es maximizar el crecimiento y la eficiencia), pero en el momento en que se produce una crisis, invoca a una ingente ayuda del gobierno, preocupado por el contagio, por la extensión de la enfermedad de un país a otro.

\section{FALLAS DE MERCADO Y REGULACIÓN ECONÓMICA}

\subsection{FALLAS DE MERCADO}

Las fallas de mercado son situaciones caracterizadas porque los mercados fallan a la hora de lograr eficiencia, en sentido económico, lo cual significa que el mercado no asigna por sí solo los recursos de manera eficiente o no conduce a la obtención de un óptimo de Pareto ${ }^{5}$. Esta situación se produce cuando el suministro que hace un mercado de un bien o servicio no es eficiente, debido a que el mercado

3 Joseph Stiglitz (1943) economista y profesor. En el 2001, George A. AKERLOF, Michael SPENCE y Joseph E. STIGLITZ (estadounidenses), obtuvieron el Premio Nobel de Economía "por sus análisis de los mercados con información asimétrica". Es conocido por su visión crítica de la globalización, de los economistas de libre mercado (a quienes llama "fundamentalistas de libre mercado") y de algunos de los organismos internacionales de crédito como el Fondo Monetario Internacional y el Banco Mundial. Es considerado como pionero en la moderna economía de la información; ha desarrollado conceptos tales como "selección adversa", "riesgo moral" y "asimetrías en la información" que actualmente son centrales en el neo institucionalismo. También hizo importantes contribuciones a la economía del sector público, la macroeconomía, la economía del comercio internacional y del desarrollo.

4 Afirma que el Fondo Monetario Internacional (FMI) es una institución pública, establecida con dinero de los contribuyentes de todo el mundo. El fondo no reporta directamente ni a los ciudadanos que lo pagan ni a aquellos cuyas vidas afecta. En vez de ello, informa a los Ministros de Hacienda y a los bancos centrales de los Gobiernos del mundo. Ellos ejercen su control a través de un complicado sistema de votación basado en buena medida en el poder económico de los países a finales de la II Guerra Mundial (Stiglitz 2008: 49).

5 La eficiencia en el sentido de Pareto (1848-1923) consiste en que las asignaciones de recurso que tienen la propiedad de que no es posible mejorar el bienestar de ninguna persona sin empeorar el de alguna otra. Es lo que normalmente se refiere en economía a la eficiencia. Para que los mercados sean eficientes en el sentido de Pareto, tiene que haber competencia perfecta. 
suministra más cantidad de lo que sería eficiente o porque el equilibrio del mercado proporciona menos cantidad de un determinado bien de lo que sería eficiente. En general, estas fallas surgen por las imperfecciones del mercado.

Evidentemente, las fallas de mercado conllevan a que surjan posibilidades para que opere un organismo regulador del Estado en la economía, ya que si se deja actuar libremente al mercado (libre oferta y demanda), no se alcanzará un óptimo de Pareto. En ese sentido, el Estado puede contribuir a resolver estas fallas de mercado regulando aquellas actividades económicas que presentan ineficiencia.

De acuerdo con Stiglitz (2000; 92) el primer teorema fundamental de la economía del bienes$\operatorname{tar}^{7}$ establece que la economía solo es eficiente en el sentido de Pareto en determinadas circunstancias o condiciones. Hay seis importantes condiciones en las que los mercados no son eficientes en el sentido de Pareto. Se denominan fallas de mercado y constituyen un argumento a favor de la intervención del Estado. Los mercados por sí solos fallan de forma evidente, y fallan con mucha frecuencia. En consecuencia, las fallas tienen muchas causas, pero seis son muy relevantes:

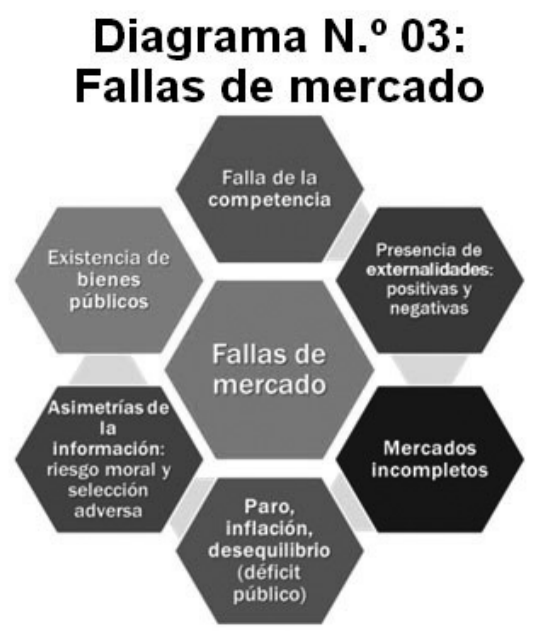

Aunque la presencia de fallas en el mercado justifica la intervención del Estado, esto no quiere decir que un determinado programa público destinado a corregir una falla del mercado sea necesariamente deseable. Para evaluar los programas públicos, debe tenerse en cuenta no solo sus objetivos sino también su ejecución. A continuación, se analiza cada una de las fallas del mercado.

\subsubsection{FALLA RELACIONADA CON LA COM- PETENCIA}

En un mercado, la competencia se genera mediante la interacción de la oferta y demanda sobre la cantidad de un determinado producto (bien o servicio).

Las fallas de mercado relacionadas con la competencia se asocian con los mercados de competencia imperfecta, como son el monopolio, el oligopolio, la competencia monopolística y el monopolio natural.

$\mathrm{Al}$ respecto, artículo $61^{\circ}$ de la Constitución Política establece expresamente: "El Estado facilita y vigila la libre competencia. Combate toda práctica que la limite y el abuso de posiciones dominantes o monopólicas. Ninguna ley ni concertación puede autorizar ni establecer monopolios (...)”.

\subsubsection{EXTERNALIDADES}

Las externalidades son actividades que afectan a terceros, positiva o negativamente, sin que estos (beneficiados o afectados) paguen o sean pagados por dichas actividades, respectivamente. Existen externalidades cuando la producción o el consumo de un bien afecta directamente a consumidores o empresas que no participan en su compra ni en su venta y cuando esos efectos no se reflejan totalmente en los precios de mercado ${ }^{8}$.

6 La economía del bienestar hace referencia a la economía normativa, en el sentido de que se preocupa del grado en el que los programas públicos sirven para cumplir los objetivos deseados, así como de la forma en que pueden lograrse los mejores resultados. La evaluación que se haga debe contemplar los efectos de los programas públicos sobre la eficiencia económica y sobre la distribución del ingreso (Urrunaga et al. 2001; 20).

7 El derecho de la competencia puede dividirse en dos ramas: derecho de la competencia propiamente dicho, que regula los procedimientos para que el mercado funcione de manera transparente entre lo que se oferta y lo que se adquiere; y, el derecho de la limitación de la competencia que estructura una serie de normas que restringen, basándose en principios y valores, la libertad de para competir y prohíbe, simultáneamente, el uso de medios pérfidos (Chanamé, 2011; 539).

8 En economía, el término técnico externalidad se refiere a las situaciones donde un intercambio de mercado impone costos o beneficios a terceros que no participan en el intercambio (Stiglitz, 2010; 46).

102/ QVIPURAMAYOC | Vol. 21(39) 2013 
Para Hal Varian (2006; 653) hay externalidad en el consumo si a un consumidor le afecta directamente la producción o el consumo de otros. Del mismo modo, existe una externalidad en la producción cuando las decisiones de una empresa o de un consumidor influyen en las posibilidades de producción de otra empresa. En ambos casos, existen externalidades negativas y positivas. A continuación, se puede observar los tipos de externalidades:

Nuestra Constitución (artículos 66 al 69) así como las leyes específicas sobre protección de los recursos naturales se enmarcan dentro del derecho a la protección misma de los recursos naturales (reservas, parques nacionales, etc.), derecho a un aprovechamiento racional de los recursos naturales, vía instituciones, mediante licencias, permisos, concesiones, limitaciones administrativas, etc; y el ejercicio de facultades sancionadoras de la autoridad que controla actividades económicas relacionadas con los recursos naturales.

Paul Krugman ${ }^{9}$ et al. $(2011 ; 220)$ sostienen que los agentes internalizan la externalidad cuando toman en cuenta los costos y las ganancias externas. Si las externalidades se internalizan completamente, entonces la asignación es eficiente a pesar de que el gobierno se haya mantenido al margen.

\subsubsection{PROBLEMAS DE INFORMACIÓN}

Para Adam Smith el mercado conduce, como si de una mano invisible se tratara, a la eficacia económica. Este postulado se sustenta en el supuesto de que la competencia es perfecta y por tanto, la información es perfecta o simétrica (no hay problemas de información). Sin embargo, en los mercados del mundo real actual existen problemas de información. En efecto, la información es incompleta y asimétrica cuando la información sobre la calidad y características de los bienes y servicios intercambiados no está distribuida de forma simétrica (igual) entre los consumidores y los productores, entonces, una de las partes de la relación económica sea comprador o vendedor tiene mejor o mayor información que la otra parte sobre una transacción. En los mercados de información asimétrica suele haber menos compradores y vendedores que cuando hay información perfecta ${ }^{10}$.

Paul Krugman (2009; 71) argumenta que el término riesgo moral tiene su origen en la industria de los seguros. Hace mucho tiempo, los aseguradores de incendios en particular observaron que los propietarios que estaban completamente asegurados contra pérdida tenían una tendencia interesante a sufrir incendios destructores, en particular cuando las condiciones cambiantes habían reducido el valor probable de su edificación en el mercado por debajo del valor cubierto por el seguro. Añade que en los años 80 hubo una especie de epidemia global de riesgo moral. Su mal manejo de las asociaciones de ahorro y préstamos fue el ejemplo clásico de la formulación de una política imprudente, de corta visión y en ocasiones corrupta (Krugman, 2009; 74).

Cabe destacar que el artículo $65^{\circ}$ de nuestra Constitución establece: "El Estado defiende el interés de los consumidores y usuarios. Para tal efecto, garantiza el derecho a la información sobre los bienes y servicios que se encuentran a su disposición en el mercado (...)”.

\subsubsection{BIENES PÚBLICOS}

En el diagrama siguiente se puede apreciar las características de los cuatro tipos de bienes así como algunos ejemplos para cada caso.

9 Paul Krugman (1953- ), economista y periodista norteamericano, cercano a los planteamientos neokeynesianos. En el año 2008 obtuvo el Premio Nobel de Economía por sus aportaciones a la teoría de la Economía Internacional y la Geografía Económica y su análisis de los patrones de comercio y la localización de la actividad económica. Se ha preocupado por replantear modelos matemáticos para resolver el problema de dónde y por qué ocurre la actividad económica. Es conocido como crítico de las políticas económicas y generales de la administración de George W. Bush. En su obra ampliada y actualizada “De vuelta a la economía de la Gran Depresión y la Crisis del 2008” publicada en el año 2008 ” reafirma sus convicciones sobre el origen de las crisis financieras y la manera como deben manejarse.

10 Joseph Stiglitz en sus investigaciones durante el último cuarto de siglo, ha demostrado que una de las razones de la invisibilidad de esa mano invisible es tan sencilla como que la mano no aparece por ninguna parte. Hasta en los países muy desarrollados, los mercados funcionan de manera considerablemente distinta a lo previsto por las teorías de los mercados perfectos. 


\section{Diagrama N. ${ }^{\circ} 04$ : Cuatro tipos de bienes con relación a la exclusión o rivalidad en el consumo}

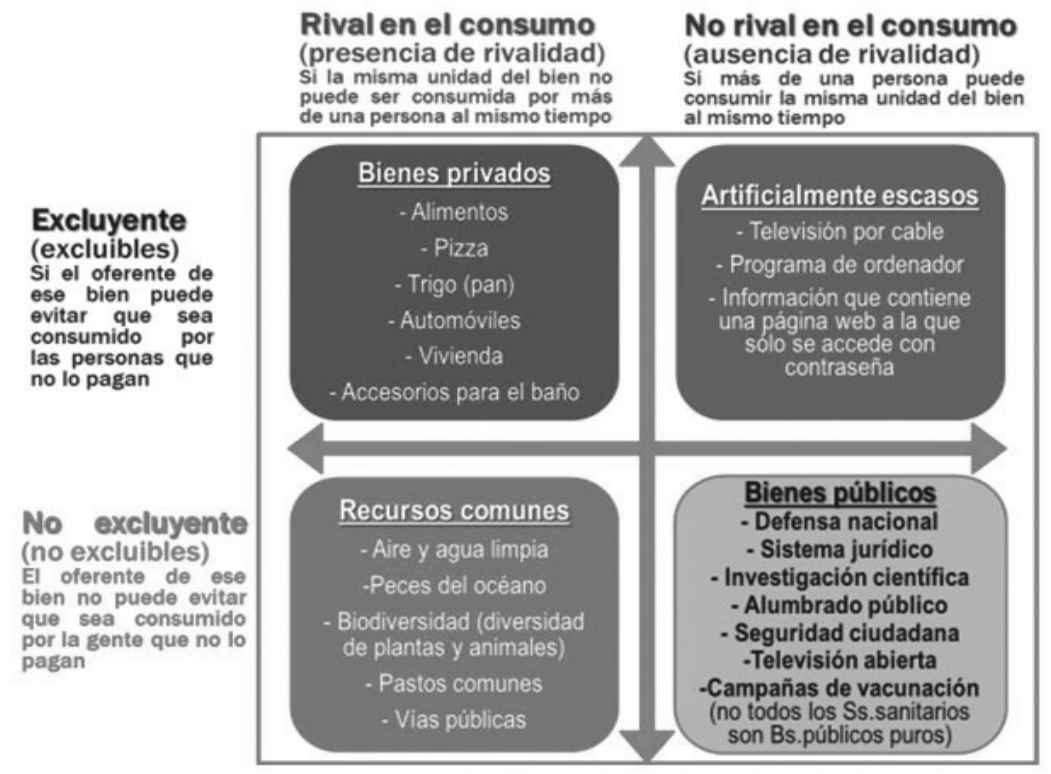

De lo anterior, se desprende que los bienes no excluyentes pueden ser: recursos comunes y bienes públicos. En palabras de Elinor Ostrom ${ }^{11}$ (2011: 77) el término Recursos de Uso Común (RUC) alude a un sistema de recursos naturales o creados por el hombre, lo suficientemente grande como para volver costoso (aunque no imposible) excluir a beneficiarios potenciales. La existencia de recursos comunes hace que el mercado sufra el problema de la sobreexplotación.

Los bienes públicos son no rivales (ausencia de rivalidad) y no excluibles en el consumo, pues no es posible impedir que una persona utilice un bien de esta naturaleza. Un bien público es un bien o servicio que se puede consumir en forma simultánea por todos y del que no se puede excluir a nadie ${ }^{12}$. En los bienes públicos la falla del mercado suele manifestarse en que se ofrece una cantidad insuficiente de dicho bien.
Debido a que los bienes públicos son no excluyentes sufren el problema del free-rider ${ }^{13}$, porque la cantidad del bien que puede consumir una persona no depende del monto que la persona paga por él. Nadie tiene un incentivo para pagar por un bien público. Por eso las empresas privadas no quieren producir estos bienes. $\mathrm{Y}$ debido a que son bienes no rivales en el consumo sería ineficiente cobrar a la gente por consumirlos.

Paul Krugman et al. $(2011 ; 239)$ afirman que los bienes públicos se ofrecen a la sociedad de formas distintas. No siempre el gobierno es el agente encargado de proporcionar estos bienes: en muchos casos el problema del free-rider se ha solucionado al margen del gobierno. Pero generalmente esas soluciones son imperfectas.

Algunos bienes públicos son ofertados a través de contribuciones voluntarias. Por ejemplo, las donaciones privadas sirven para financiar una bue-

11 Elinor Ostrom (1933 - 2012) fue una politóloga estadounidense. Obtuvo el Premio Nobel de Economía en el año 2009, compartido con Oliver E. Williamson, por "su análisis de la gobernanza económica, especialmente de los recursos compartidos".

12 Los bienes públicos son el ejemplo extremo de externalidad positiva. Los bienes públicos benefician de una manera indivisible a toda una sociedad, independientemente de que las personas deseen o no comprarlos.

13 En la literatura económica existen personas consideradas como parásitos (free-rider), que consumen el bien público sin pagar por él, es decir, son aquellas personas que reciben el beneficio de un bien pero evitan pagarlo.

104/ QVIPURAMAYOC|Vol. 21(39) 2013 
na parte de la investigación científica. Del mismo modo, algunos bienes públicos son ofertados por agentes privados, por ser ellos quienes producen este tipo de bienes, y de alguna manera son capaces de obtener ingresos de forma indirecta. El ejemplo clásico es la televisión por cable.

Krugman et al. (2011: 240) sostienen que la teoría económica establece que una de las razones más importantes por la que el Estado debe intervenir en la economía es para proporcionar bienes públicos a la sociedad.

El Estado normalmente ha desempeñado un papel importante en la provisión de educación, pese a no ser un bien público puro. Los argumentos de la intervención del Estado en la educación se explican porque la educación inadecuada está relacionada con toda una variedad de problemas sociales y conductas antisociales.

Los Estados que gastan menos en educación por alumno tienden a obtener peores resultados, medidos mediante los ingresos (...). Uno de los fines que subyacen a la provisión (financiación) pública de la educación es fomentar la igualdad de oportunidades (Stiglitz 2000: 450-62).

Sobre este aspecto, nuestra Constitución consagra el derecho a la igualdad en el artículo $2^{\circ}$ inciso 2. Asimismo, el Plan Bicentenario: El Perú hacia el 2021, contempla como eje esencial la igualdad de oportunidades y acceso a los servicios básicos.

\subsubsection{MERCADOS INCOMPLETOS}

Los bienes y los servicios públicos puros no son los únicos que los mercados suministran inadecuadamente. Existen mercados incompletos cuando los mercados privados no suministran un bien o un servicio, aun cuando el costo de suministrarlo sea inferior a lo que los consumidores están dispuestos a pagar, por lo que hay una falla del mercado.

Algunos economistas están convencidos que los mercados privados han funcionado especialmente mal en la provisión de seguros y préstamos a las pequeñas empresas, lo que ha motivado en la mayoría de países la intervención del Estado a través de la regulación.

Específicamente, con relación a las pequeñas empresas, nuestra Constitución en la parte final del artículo 590 dispone lo siguiente: “( ... ) El Estado brinda oportunidades de superación a los sectores que sufren cualquier desigualdad; en tal sentido, promueve las pequeñas empresas en todas sus modalidades".

\subsubsection{PARO, INFLACIÓN Y DESEQUILIBRIO (DÉFICIT PÚBLICO)}

Tal vez el síntoma más admitido de las fallas de mercado sea el elevado índice de desempleo ${ }^{14}$ que ha acosado a las economías capitalistas en los últimos doscientos años, aún cuando hayan sido mucho más moderas a partir de la Segunda Guerra Mundial (Stiglitz 2000: 703).

Si los mercados no son capaces de generar pleno empleo, no significa necesariamente que deba intervenir el Estado. La mayor parte de economistas utilizan los elevados niveles de paro (tanto de trabajadores como de máquinas) como evidencia de que algo no funciona bien en el mercado. No obstante, existen medidas mediante las cuales el Estado puede mejorar el funcionamiento de la economía.

Cuando el gasto público excede los ingresos fiscales, se genera un déficit fiscal, lo cual implica presiones al alza del nivel general de precios ${ }^{15}$. Por tal razón, la reducción del déficit puede tener consecuencias importantes sobre el crecimiento económico. Para algunos, disminuir el déficit por medio del aumento de los impuestos reduce el ahorro. Otros consideran que la reducción del déficit recorta la inversión pública y perjudica el crecimiento económico, ya que estas inversiones generan elevados rendimientos y aumentan la inversión privada.

14 El desempleo está formado por la población activa (en edad y capacidad de trabajar) que buscan activamente un puesto de trabajo, sin encontrarlo.

15 La inflación es el aumento o crecimiento sostenido del nivel general de precios de los bienes y servicios a lo largo del tiempo, ocasionando una pérdida del poder adquisitivo. Desalienta la inversión productiva y favorece la especulación. Tiene incidencia apreciable sobre las tasas de interés y el tipo de cambio. 
Debido a estos problemas estructurales, países como el nuestro han constitucionalizado temas como la prohibición del Banco Central de conceder financiamiento al erario (artículo $84^{\circ}$ ). La historia económica ha demostrado que cuando los bancos centrales no tienen independencia en muchas ocasiones se ven tentados a financiar al erario, rompiendo una regla básica en el ámbito monetario: la disciplina monetaria. Asimismo, se ha dado rango constitucional a que la finalidad del Banco Central es preservar la estabilidad monetaria ${ }^{16}$.

\subsection{REGULACIÓN ECONÓMICA}

La regulación económica entendida como restricciones o limitaciones legales que se imponen a los agentes que participan en un mercado se justifica ante la presencia de fallas de mercado generadas por la presencia de externalidades, existencia de bienes públicos, falla de la competencia, asimetrías de la información, mercados incompletos, etc.

Sin embargo, las tendencias han sido: 1) Regulación excesiva (tendencia a que las regulaciones obsoletas pervivan, por los intereses que siempre surgen a su amparo); 2) Retroalimentación de la regulación, al querer corregir sus múltiples efectos negativos por nuevas regulaciones. Estas tendencias se basan a su vez, en una compleja trama de intereses que se ocultan tras toda la regulación: intereses políticos, de los burócratas y de los grupos de interés que crecen a su amparo.

Sobre el particular, es necesario precisar que la competencia es el objetivo prioritario y la regulación el instrumento necesario para defender la competencia. Para que exista y funcione el mercado con corrección, es preciso en muchos casos que el Estado cree un sistema jurídico-institucional adecuado.

Solo cuando el Estado asume sus funciones de creación de un marco institucional que impone limitaciones y deberes de hacer a aquellos que actúan en estos sectores, puede originarse un mercado, imperfecto si se quiere, pero más eficiente que la gestión pública monopólica hasta ahora existente.
La regulación por parte del Estado se justifica en aquellos mercados donde presentan fallas. En esa orientación, el Tribunal Constitucional en el EXP. No 0008-2003-AI/TC F.J. 35 argumenta que la Constitución reserva al Estado, respecto del mercado, una función supervisora y correctiva o reguladora. Es más, añade en el F.J. 36 que la función reguladora del Estado se encuentra prevista en el artículo $58^{\circ}$ de la Constitución, cuyo tenor es que "la iniciativa privada es libre. Se ejerce en una economía social de mercado. Bajo este régimen, el Estado orienta el desarrollo del país, y actúa principalmente en las áreas de promoción de empleo, salud, educación, seguridad, servicios públicos e infraestructura [... ]" Por su parte, el artículo $59^{\circ}$ establece que el Estado estimula la creación de riqueza y garantiza la libertad de trabajo, comercio e industria.

Para Krugman $(2012 ; 71)$ gracias a la regulación, la banca manejó la concesión de préstamos con mucha más cautela de la que había empleado antes de la Gran Depresión. Del mismo modo, Stiglitz $(2010 ; 144)$ sostiene que los mercados hipotecarios daneses proporcionan una alternativa que ha funcionado bien para ese país a lo largo de más de dos siglos. Las tasas de impago son bajas, y los productos estandarizados aseguran una fuerte competencia -con bajos tipos de interés y bajos costos de transacción-. Una de las razones de la baja tasa de impagos en Dinamarca es una normativa estricta -los prestatarios pueden pedir prestado como mucho el $80 \%$ del valor de la casa- $y$ el originador tiene que soportar las primeras pérdidas $(. .$.$) .$

\section{PAPEL ECONÓMICO DEL ESTADO 4.1 ESTADO Y GOBIERNO}

Para Víctor García $(2008$; 223) el Estado alude a la existencia de una sociedad política, independiente y organizada, que posee la titularidad soberana, abstracta y permanente del ejercicio del poder, y cuyo fin consiste en el cumplimiento y racionalización de la vida comunitaria; en función de lo cual establece un orden jurídico coactivo.

16 Preservar la estabilidad monetaria implica mantener la inflación bajo control, ya que no solo influye negativamente el nivel de producción, sino que genera un impuesto inflación (pérdida de capital que sufren los agentes económicos con su dinero como resultado de la inflación) que afecta significativamente a los sectores de bajos ingresos.

106/ QVIPURAMAYOC|Vol. 21(39) 2013 
En consecuencia, el Estado es una sociedad política autónoma y organizada para estructurar la convivencia, en razón de que se trata de un conjunto permanente de personas que se relacionan por la necesidad de satisfacer imperativos de supervivencia y progreso común. Para ello requiere de un sistema de relaciones coexistenciales dotado de fuerza social y basado en una relación jerárquica: gobernantes y gobernados.

El gobierno alude al conjunto de órganos establecidos en la Constitución de un Estado, a efectos de viabilizar el ejercicio de la soberanía (...). Es el poder político organizado que ejerce dominio sobre el territorio y control sobre la población de un Estado. Los responsables de la conducción de los órganos de gobierno (Ejecutivo, Legislativo, Judicial) reciben la denominación de gobernantes; de ahí que tradicionalmente se conecte dicha expresión con la pluralidad de personas ejercientes del poder político; $y$ por tanto, configurantes físicos de la administración y orientación de la marcha del Estado (García 2008: 224-6).

Debido a ello, en términos generales todos tenemos una cierta idea de cuáles son los órganos que integran el Estado: el Parlamento, el Gobierno, el Tribunal Supremo y una multitud de instituciones y organismos públicos autónomos.

La diferenciación entre los órganos del Estado y las entidades privadas se puede analizar a través de dos importantes características:

1) La legitimidad de la persona que ocupa el cargo emana, directa o indirectamente, del proceso electoral, en cambio los responsables de la administración de una empresa privada son elegidos por los accionistas.

2) El Estado posee determinados derechos de coerción ${ }^{17}$ de los que carecen las instituciones privadas. Tiene derecho a obligarnos a pagar impuestos ( $y$ en caso contrario, a embargar nues- tras propiedades y/o encarcelarnos). Tiene derecho a expropiar tierras para uso público.

El Estado tiene virtudes: su capacidad para utilizar la coerción significa que puede hacer algunas cosas que están vedadas a las instituciones privadas. Pero también tiene defectos (Stiglitz, 2000; 21).

Por tanto, comprender estas virtudes y defectos es esencial para averiguar qué papel debe desempeñar el Estado en la economía y cómo puede cumplirlo más eficazmente.

\subsection{INCENTIVO PARA LA INTERVENCIÓN DEL ESTADO: FALLAS DE MERCADO}

Las formas más corrientes de intervención del Estado en la economía son aquellas mediante las cuales los gobiernos de turno regulan el mercado de trabajo, fijando un salario mínimo así como el control de precios de los artículos de primera necesidad. Un caso extremo de intervencionismo se produce cuando el sector público se dedica a la producción de una importante fracción de los bienes y servicios que se ofrecen en la economía (sistema de planificación central) $)^{18}$.

Sin lugar a dudas, la Gran Depresión, fue el acontecimiento que más cambió la actitud hacia el Estado. Se llegó al convencimiento (y con razón) de que los mercados habían fallado claramente, lo que dio lugar a enormes presiones para que el Estado hiciera algo. John Maynard Keynes, que escribió en medio de la Gran Depresión, creía firmemente no solo que el Estado debía intervenir para hacer frente a las depresiones económicas sino que también podía hacerlo. Opinaba que la economía de mercado llegaría a cometer tropiezos y cuando este tropezase con dificultades, los mecanismos del mercado no funcionarían, por lo tanto el gobierno debía intervenir.

17 Manifestación del poder estatal que tiene por objeto la prevención o en su caso la reparación. El Derecho y los sistemas legales, en general, se sustentan en la amenaza de la sanción más que en la utilización de la propia violencia.

18 La Constitución de 1979 contemplaba la intervención del Estado en la economía. Disponía expresamente lo siguiente "En situaciones de crisis grave o de emergencia el Estado puede intervenir la actividad económica con medidas transitorias de carácter extraordinario” (artículo 132o). 


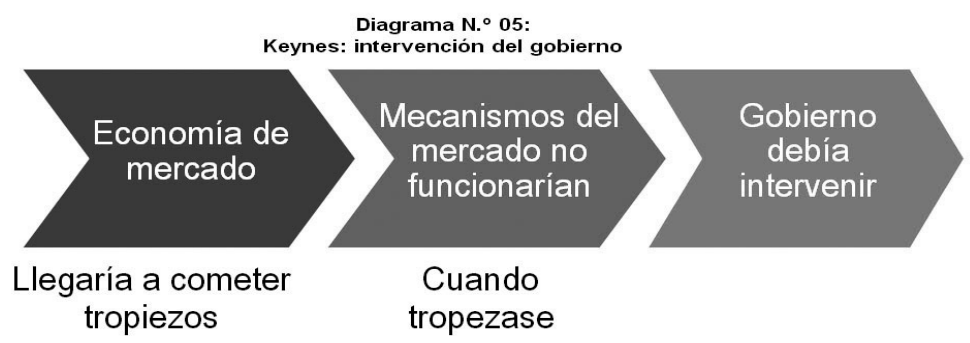

Para Keynes el gasto público debería ir a contracorriente, esto es, en tiempos de bonanza el gobierno debe acumular superávit fiscal y en tiempos de crisis, como la gran depresión, se debe aumentar el gasto público, entrar en déficit para devolver el poder adquisitivo a los trabajadores.

En la realidad, el libre funcionamiento de los mercados no puede cumplir con todas las funciones económicas, por lo que es necesario que el Estado intervenga a través de la regulación en algunas áreas de la actividad económica.

Los banqueros centrales son un club propenso a modas pasajeras. Tienden a ser conservadores $y$, mayoritariamente, no creen en la intervención del gobierno en el mercado. Lo cual es curioso, ya que su cometido principal es fijar uno de los precios más importantes de la economía, el tipo de interés. Por tanto, la cuestión no es si el gobierno intervendrá, sino cómo y cuándo (Stiglitz 2010: 306-7).

Diagrama N. ${ }^{\circ} 06$ :

Stiglitz: intervención de los bancos centrales a través de la tasa de interés

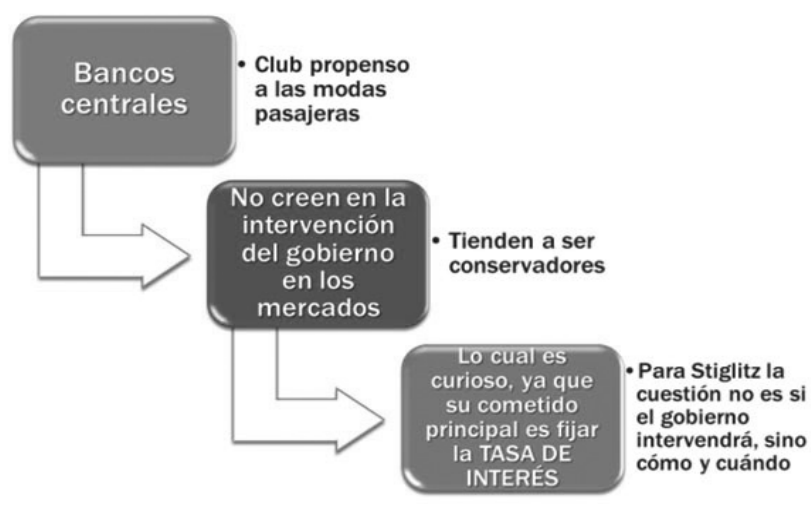

\subsection{FORMAS DE INTERVENCIÓN DEL ESTADO}

Una vez que se han identificado las fallas en el mercado, existen diversas formas de actuaciones del Estado que pueden resolver el problema. Estas pueden dividirse en tres categorías:

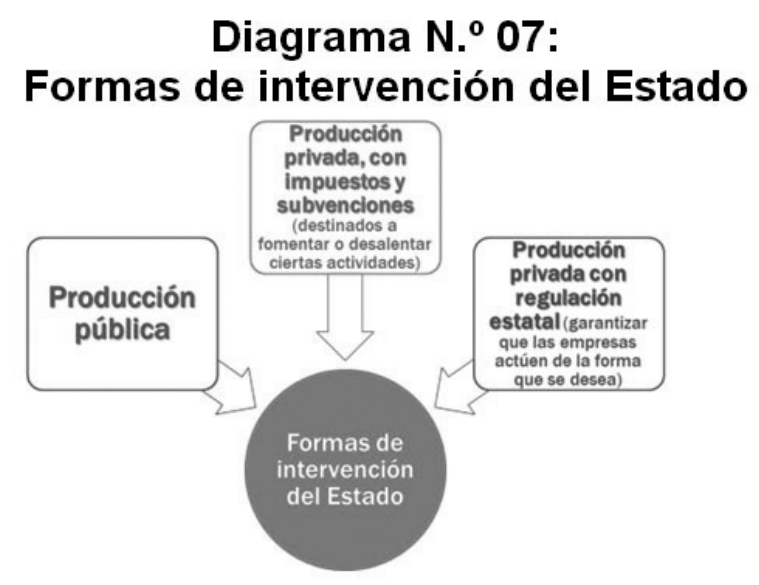

108/ QVIPUIRAMAYOC | Vol. 21(39) 2013 
La intervención del Estado a través de la producción pública, que viene a ser una forma extrema de intervencionismo del Estado en la economía, se encuentra asociado con la planificación central.

En cambio, el de producción privada con regulación estatal constituye un modelo en el que se garantiza la iniciativa privada libre dentro de los límites que establece la regulación. Esto se relaciona con la economía social de mercado, conocido jurídicamente, como Estado social de derecho. Surge en la década de 1930 como respuesta al colapso de las economías puras de mercado. Se sustenta en las teorías de Keynes.

\section{EQUILIBRIO CORRECTO ENTRE ESTA- DO Y LIBRE MERCADO}

\subsection{REGULACIÓN DEL GOBIERNO YMEJOR FUNCIONAMIENTO DE LOS MERCADOS}

En el contexto actual en el que vivimos existe una pugna ideológica entre quienes sostienen que se debe reducir al mínimo la intervención del Estado en la economía (posición de los liberales) y aquellos como los keynesianos que argumentan que el gobierno debe asumir un rol importante, si bien limitado, no solo para corregir las fallas de mercado, sino también para tender hacia un grado más alto de justicia social. Hoy el reto consiste en lograr un equilibrio correcto: entre Estado y mercado.

En efecto, los países deben tratar de lograr un equilibrio entre el libre mercado, que impulse el crecimiento económico sostenido de una nación y la intervención del Estado, enfocada básicamente en políticas públicas de carácter social, aspecto fundamental para alcanzar el desarrollo económico.

Diagrama N. ${ }^{\circ} 08$ :

Reto: lograr equilibrio correcto entre el Estado y el libre mercado

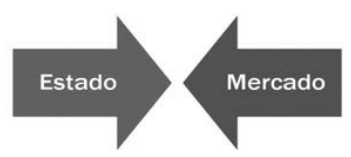

Bajo esta perspectiva, la regulación ejercida por el gobierno puede y suele desempeñar un papel importante con la finalidad de lograr un mejor funcionamiento de los mercados, siempre y cuando constituya un instrumento que facilite y vigile la libre competencia.

Para Jeffrey Sachs, a finales del siglo XX se produjo una revolución capitalista. La economía de mercado, el sistema capitalista, se convirtió en el único sistema posible en la mayor parte del mundo. Esta revolución económica ha definido la riqueza y la suerte de las naciones y condicionará el futuro del planeta ${ }^{19}$.

Las políticas liberales implementadas sobre todo en los años ochenta condujeron a mantener un Estado limitado. Sin embargo, a finales de los años noventa y especialmente en la década anterior, cada vez existe un mayor consenso de la importancia del papel del Estado en la economía ${ }^{20}$.

\subsection{ROL FUNDAMENTAL DEL ESTADO}

El tema esencial de la economía mundial del siglo XXI consiste en determinar el rol del Estado. Se requiere reconstruir una sociedad donde el Estado y el mercado se encuentren más equilibrados. Definitivamente, un mayor equilibrio puede conllevarnos a una economía más eficiente y sobre todo económicamente estable.

Durante los últimos 35 años, los economistas han logrado una mejor comprensión de cuándo funcionan bien los mercados y cuándo no. Mucho depende de los incentivos: ¿cuándo proporcionan los mercados los incentivos correctos?, ¿cuándo coinciden las recompensas privadas con los beneficios sociales? y ¿cómo puede el gobierno ayudar a que coincidan?

Marco institucional. Para algunos solo hace falta garantizar los derechos de propiedad y aplicar los contratos. Ambas cosas son necesarias pero no suficientes, y plantean algunos temas claves, por ejemplo,

19 Documental "Batalla por la Economía Mundial” (Barker 2002).

20 Concretamente a raíz de la crisis de 2008, Stiglitz (2010: 39) sostiene que los responsables del sector financiero a menudo culpan a la Reserva Federal por permitir que los tipos de interés permanecieran bajos durante tanto tiempo. Pero este intento particular de trasladar la culpa es peculiar: ¿Qué otro sector diría que la razón de que sus beneficios fueran tan bajos y de que su rendimiento fuera tan malo es que los costos de sus inputs (acero, salarios) son demasiado bajos?. ¡Y sin embargo parece que los banqueros se quejan de que la FED pusiera el dinero demasiado barato. 
sobre la exacta definición y el alcance de los derechos de propiedad. La propiedad no da derecho a hacer absolutamente todo lo que a uno le plazca.

Pleno empleo y una economía estable. Hacer que el mercado funcione es una de las responsabilidades del Estado, y las manifestaciones más obvias de falla de mercado son los episodios periódicos de desempleo y de infrautilización de las capacidades, las recesiones y las depresiones que han caracterizado al capitalismo.

Promoción de la innovación. Hay algunos bienes que el mercado espontáneamente nunca suministrará en cantidad suficiente. Esto incluye bienes públicos, de cuyos beneficios pueden gozar todos los miembros de la sociedad, y entre ellos están ciertas innovaciones esenciales.

Protección social y seguridad. A una aseguradora no le gusta tener que pagar facturas, y por tanto, hará todo lo posible por descubrir quién corre el riesgo. Esta es una de las razones por las cuales el gobierno continuará teniendo un papel esencial en esos mercados de seguros.

Investigación. De acuerdo con Stiglitz (2010: 251) sin la ayuda del gobierno, habría poca investigación básica, y por supuesto reducia en lo referido a enfermedades de los pobres. En la economía innovadora del siglo XXI, el gobierno debe asumir un rol más importante para sufragar la investigación básica sobre la cual descansa todo el edificio; debe, por ejemplo, a través de subvenciones y premios que incentiven la investigación que más responda a las necesidades nacionales; y para lograr un régimen de la propiedad intelectual más equilibrado.

\section{CONCLUSIONES}

1) Las fallas de mercado se refieren a situaciones concretas en las que están presentes todas o algunas de las causas de ineficiencia: cuando no se dispone de suficiente o adecuada información (información imperfecta o asimétrica), existencia de bienes públicos, presencia de externalidades, mercados incompletos, déficit público.

2) La regulación ejercida por el gobierno puede $y$ suele desempeñar un papel importante con la finalidad de lograr un mejor funcionamiento de los mercados, siempre y cuando constituya un instrumento que facilite y vigile la libre competencia. En tal sentido, para que funcionen bien los mercados, se requiere de un marco institucional adecuado; solo así, pueden corregirse las imperfecciones del mercado.

3) El libre mercado no puede cumplir con todas las funciones económicas, por lo que es necesario que el Estado intervenga a través de la regulación en algunas áreas de la actividad económica, sobre todo en aquellos mercados que presentan fallas. Sin embargo, una actividad no debe regularse excesivamente porque conlleva a mantener intereses y privilegios, que crecen al amparo de la clase política, los burócratas del Estado y los grupos empresariales.

\section{REFERENCIAS BIBLIOGRÁFICAS}

1. BARKER, Greg (guionista) (2002). Commanding Heights: The Battle for the World Economy / Batalla por la Economía Mundial. Documental. Directores: Greg Barker y William Cran.

2. CHANAMÉ, Raúl (2011). La Constitución comentada. Sexta edición. Lima. Editorial ADRUS.

3. GARCÍA, Víctor. Teoría del Estado y Derecho Constitucional. Segunda edición. Lima. Palestra Editores.

4. KRUGMAN, Paul (2012). Acabemos ya con la crisis. Colombia. Editorial Crítica.

5. KRUGMAN, Paul (2009). De vuelta a la economía de la gran depresión y la crisis del 2008. Colombia. Grupo Editorial Norma S.A.

6. KRUGMAN, Paul; WELLS, Robin; OLNEY Martha L. (2011). Introducción a la Economía. España. Editorial Reverté S.A.

7. OSTROM, Elinor (2011). El gobierno de los bienes comunes. Segunda edición en español. México. Fondo de Cultura Económica.

8. ROLL, Eric (1994) Historia de las doctrinas económicas. Tercera edición en español. México. Fondo de Cultura Económica. 
FALLAS DE MERCADO Y REGULACIÓN ECONÓMICA: ¿LA REGULACIÓN EJERCIDA POR EL GOBIERNO PERMITE LOGRAR UN MEJOR FUNCIONAMIENTO DE LOS MERCADOS?

9. SACHS, Jeffrey (2008). Economía para un planeta abarrotado. Buenos Aires. Editorial Sudamericana S.A.

10. SMITH, Adam (1958). Investigación sobre la naturaleza y causas de la riqueza de las naciones. México. Segunda edición en españo. Fondo de Cultura Económica.

11. STIGLITZ, Joseph E. (2010). Caída libre. México. Santillana Ediciones Generales.

12. STIGLITZ, Joseph E. (2008). El malestar de la globalización. España. Santillana Ediciones Generales.
13. STIGLITZ, Joseph E. (2000). La Economía del Sector Público. España. Antoni Bosch, editor S.A.

14. TRIBUNAL CONSTITUCIONAL EXP. N. ${ }^{\circ}$ 0008-2003-AI/TC.

15. URRUNAGA, Roberto; HIRAOKA, Tami; RISSO, Antonio (2001). Fundamentos de economía pública. Lima. Universidad del Pacífico.

16. VARIAN, Hal (2006). Microeconomía Intermedia. Séptima edición. España. Antoni Bosch, editor S.A. 